Revista Ciencia \& Desarrollo 2015; 20: 36-41 / ISSN 2304-8891

\title{
CALIDAD MICROBIOLÓGICA DE PRODUCTOS NATURALES ENCAPSULADOS EXPENDIDOS EN CASAS NATURISTAS DE LA CIUDAD DE TACNA
}

\author{
MICROBIOLOGICAL QUALITY OF NATURAL ENCAPSULATED \\ PRODUCTS DISPENSED AT HEALTH FOOD HOUSES TACNA
}

\author{
${ }^{1}$ César Julio Cáceda Quiroz; ${ }^{2}$ Sergio Enrique Samillán Fernández
}

\begin{abstract}
RESUMEN
Los productos naturales están teniendo una gran acogida en todas partes del mundo, incluido el Perú, debido a esta gran demanda se han creado muchos laboratorios que los fabrican, no obstante no todos ellos elaboran productos de calidad, y muchos de ellos venden sus productos sin tener un registro sanitario; trabajos de investigación han revelado la presencia de contaminación en productos farmacéuticos de origen natural, siendo esta la razón por la cual se plantea el siguiente objetivo: Determinar la calidad microbiológica de los productos naturales expendidos en la ciudad de Tacna; y para ello se basó en los límites propuestos por la Organización Mundial de la Salud (OMS), siguiendo el protocolo de la ICMSF (2000) donde se evaluó el recuento de aerobios mesófilos viables (RAMV), recuento de hongos, investigación de Escherichia coli, investigación de Pseudomonas aeruginosa, investigación de Staphylococcus aureus y para el caso de Salmonella spp se usó la guía de los estándares internacionales según ISO 6579; donde se obtuvieron como resultados: ausencia de todos los patógenos, pero en el RAMV se encontró que el $84,61 \%$ de las muestras sobrepasaron los límites permisibles, al igual que el 92,3\% en el recuento de hongos; asimismo el 30,77\% de las muestras analizadas no presentaron número de registro sanitario. De lo encontrado se llegó a la conclusión de que los productos naturales analizados no cuentan con las condiciones mínimas para su venta al público, siendo un riesgo para la salud pública de sus consumidores al poder enfermarse con posibles patógenos oportunistas por una contaminación de origen natural.
\end{abstract}

Palabras clave: Calidad microbiológica, encapsulados, productos naturales.

\begin{abstract}
Natural products are having a great reception all over the world, including Perú, due to this high demand has created many laboratories that manufacture, however not all of them produce quality products, and many of them sell their products have a health record; Research has revealed the presence of contamination in pharmaceutical products of natural origin, this being the reason why the next target arises: To determine the microbiological quality of natural products dispensed in the city of Tacna; and it was based on the limits proposed by the World Health Organization (WHO), following the protocol of the ICMSF (2000) where the count of viable aerobic mesophilic (RAMV), mold count, investigation of Escherichia coli was evaluated, research Pseudomonas aeruginosa, Staphylococcus aureus and investigation in the case of Salmonella spp guide used international standards ISO 6579; which they were obtained as results: absence of all pathogens, but in RAMV found that $84,61 \%$ of the samples exceeded the permissible limits, as $92,3 \%$ in the mold count; also $30,77 \%$ of the analyzed samples showed no veterinary approval number. What I found it was concluded that natural products tested do not have the minimum conditions for sale to the public, being a risk to public health of its consumers to power sick with potential opportunistic pathogens by natural pollution.
\end{abstract}

Keywords: Microbiological quality, encapsulated, natural products.

\section{INTRODUCCIÓN}

El uso de plantas en la búsqueda de la salud, es tan antiguo como el ser humano; todas las civilizaciones desde las más antiguas hasta las más avanzadas han visto en la naturaleza la fuente primaria de una vida saludable, gracias a esta visión los productos naturales vienen generando altas demandas en todo el mundo. El Perú también se encuentra inmerso en este contexto, la comercialización de los productos naturales se viene dando a gran escala, estos productos

Microbiólogo. Laboratorio de Microbiología. Docente de la Facultad de Ciencias de la Universidad Nacional Jorge Basadre Grohmann. TacnaPerú.

'Egresado de Biología Microbiología. Facultad de Ciencias de la Universidad Nacional Jorge Basadre Grohmann. Tacna-Perú. 
Cáceda, C. \& Samillán S. Calidad microbiológica de productos naturales encapsulados expendidos en casas naturistas de la ciudad de Tacna.

son elaborados en laboratorios de fitofármacos, apoyados por distribuidoras nacionales o internacionales (Valenzuela, 2005).

La entidad encargada de velar por el control y la vigilancia de estos productos es la Dirección General de Medicamentos Insumos y Drogas (DIGEMID) la cual viene cumpliendo este rol desde la aprobación del Decreto Supremo 010-97-S.A. de la Ley 26842, en Diciembre de 1997. A pesar de esto, En el año 2005 había en promedio 285 empresas (nacionales y extranjeros) que elaboraban y expendían productos naturales, algunos registrados en (DIGEMID) como "productos naturales" o en la Dirección General de Salud Ambiental (DIGESA) como "complementos o suplementos nutritivos"; otros sin ningún tipo de permiso, usando muchas veces como materia prima recursos naturales que tienen poca garantía y a cargo de personas con poca preparación en el área (Valenzuela, 2005); estos hechos ponen en duda hasta la actualidad la calidad de los productos naturales pudiendo repercutir negativamente en la salud de la población, agravándose esta situación cuando en algunos casos se suele destinar estos productos naturales a personas inmunodeprimidas (Długaszewska, et al, 2008; Ratajczak, et al., 2014; Burt \& Kroes, 2014) siendo un riesgo para esas personas al estar estos productos contaminados por patógenos o, más específicamente, por sus metabolitos producidos, pudiendo inactivar el producto natural (Ratajczak, et al., 2014), Además, los productos naturales son tomados por personas de cualquier edad no habiendo una restricción para su consumo en la mayoría de las etiquetas observadas.

Un estudio en Madrid encontró enterobacterias en productos farmacéuticos con materia prima de origen natural, pero no a E. coli; por lo que esta contaminación no era fecal, sino por la materia prima de origen natural (agua, suelo, etc.) (Rosa, et al., 1995); siendo estos resultados similares al estudio realizado por Sanchez Pino, (2004) y Ratajczak et al., (2014) los cuales hallaron que las muestras farmacéuticas orales superaban los límites máximos permisibles dados por la Farmacopea Europea en donde indicaron que la fuente de contaminación de la materia prima era de origen natural, siendo la fuente el medio ambiente de donde procedian éstos (agua y/o tierra), por tal hubo contaminación pero no estaba asociada necesariamente al hombre ni al proceso de la producción de estos productos, sino a la naturaleza de la materia prima.

Las infecciones por medicamentos farmacológicos se producen esporádicamente, teniendo éstos un control más estricto que los productos naturales, pero a pesar de eso, se detectó casos documentados de salmonelosis por consumo de tabletas tiroideas y polvo de pancreatina, además de la presencia de P. aeruginosa en pomada de hidrocortisona (Ratajczak, et al., 2014), con todo esto cabe la pregunta ¿Cómo será la calidad microbiológica en los productos naturales expendidos en las casas naturistas de la Ciudad de Tacna?

\section{MATERIALY MÉTODO}

\section{Obtención de la muestra}

Las muestras analizadas fueron cápsulas de productos naturales, las cuales se encontraban en frascos de plástico, la obtención de la muestra se realizó a través de los deco- misos realizados por la Dirección Regional de Medicamentos Insumos y Drogas (DIGEMID), en las diferentes casas naturistas de la ciudad de Tacna en los meses de Junio a Diciembre del 2014. Para la elección de las diferentes muestras, se tuvo en cuenta aquellas que eran más solicitadas por la población tacneña durante los periodos de estudio, siendo éstas: Riñosan, Moringa, Glucosamin, Quemador de grasa, Higasan, Yacon, Alcachofa, Graviola, Noni, Demoledor de grasas, Prostasan, Hercampuri y Tos-Asma bronquios los cuales pertenecieron a los siguientes laboratorios: Laboratorio Natura, Hoja de oro, Oasis - salud y Oasis de la salud.

\section{Análisis microbiológico}

Los resultados microbiológicos encontrados se compararon con los límites establecidos por la Organización Mundial de la Salud para productos medicinales herbales de uso oral (tabla 1).

Tabla 1. Límites microbiológicos recomendados para formas orales de productos naturales

\begin{tabular}{lc}
\hline \multicolumn{1}{c}{ Agente Biológico } & Requisito OMS formas orales \\
\hline Bacterias aerobias mesófilas viables & No más de 10000 \\
Hongos por $1 \mathrm{~g} .0 \mathrm{ml}$ & No más de 100 \\
Salmonella sppen $10 \mathrm{~g}$. & Ausencia \\
Eschericbia colien $1 \mathrm{~g} .0 \mathrm{ml}$ & Ausencia \\
Staphylococcus aureus $\mathrm{en} 1 \mathrm{~g} .0 \mathrm{ml}$ & Ausencia \\
Pseudomonas aeruginosa en $1 \mathrm{~g} .0 \mathrm{ml}$ & Ausencia
\end{tabular}

Fuente: Organización mundial de la salud (OMS) citado por Zavaleta (1999).

Los 13 productos naturales encapsulados fueron analizados por duplicado de acuerdo a los siguientes ensayos microbiológicos:

\section{Recuento total de aerobios mesófilos viables (RAMV)}

Se usó el Plate Count Agar (PCA - Merck), usando la técnica de recuento estándar en placa, incubándolos a 29$31^{\circ} \mathrm{C}$ por $48 \pm 3$ horas; dando los resultados en unidades formadoras de colonias por gramo (ufc/g) (ICMSF, 2000).

\section{Recuento de hongos}

Se utilizó el Agar Extracto de levadura glucosa oxitetraciclina (OGYE - Merck), usando la técnica de recuento en placa de siembra por extensión en superficie, incubándolas a temperatura ambiente $\left(25^{\circ} \mathrm{C}\right)$ por 5 a 7 días; dando los resultados en unidades formadoras de propágulo por gramo (ufp/g) (ICMSF, 2000).

\section{Investigación de E. coli}

Se realizó mediante la técnica de Número Más Probable haciendo las pruebas presuntivas y confirmativas para la determinación de Coliformes totales (ver tabla 3) según la ICMSF (2000), para luego sembrar en Agar Endo y su posterior identificación con pruebas bioquímicas (IMViC).

\section{Investigación de Staphylococcus aureus}

Se utilizó el Agar Baird Parker (Merck), usando el asa de Drigalsky se extendió $0,1 \mathrm{ml}$ de inóculo vertido de las respectivas diluciones en placas de agar fundido, se las incu- 
Cáceda, C. \& Samillán S. Calidad microbiológica de productos naturales encapsulados expendidos en casas naturistas de la ciudad de Tacna.

Tabla 2. Calidad microbiológica de los productos naturales encapsulados

\begin{tabular}{|c|c|c|c|c|c|c|c|}
\hline \multirow{2}{*}{$\begin{array}{l}\mathrm{N}^{\circ} \text { de } \\
\text { muestra }\end{array}$} & \multirow[b]{2}{*}{ Producto } & \multicolumn{6}{|c|}{ Prueba microbiológica } \\
\hline & & A: ufc/g. & B: ufp/g. & $\mathrm{C}: 10 \mathrm{~g}$. & $\mathrm{D}: 1 \mathrm{~g}$. & E:ufc/g. & F: $1 \mathrm{~g}$. \\
\hline 1 & Riñosan & $1,6 \times 10^{4}$ & $2,9 \times 10^{3}$ & Ausencia & Ausencia & Ausencia & Ausencia \\
\hline 2 & Moringa & $2,6 \times 10^{3}$ & $1,1 \times 10^{2}$ & Ausencia & Ausencia & Ausencia & Ausencia \\
\hline 3 & Glucosamin & $1,2 \times 10^{4}$ & $2,6 \times 10^{3}$ & Ausencia & Ausencia & Ausencia & Ausencia \\
\hline 4 & Quemador de grasa & $5,5 \times 10^{3}$ & $3,0 \times 10^{2}$ & Ausencia & Ausencia & Ausencia & Ausencia \\
\hline 5 & Higasan & $1,3 \times 10^{5}$ & $3,8 \times 10^{4}$ & Ausencia & Ausencia & Ausencia & Ausencia \\
\hline 6 & Yacon & $1,8 \times 10^{5}$ & $1,7 \times 10^{4}$ & Ausencia & Ausencia & Ausencia & Ausencia \\
\hline 7 & Alcachofa & $8,7 \times 10^{5}$ & $5,0 \times 10^{4}$ & Ausencia & Ausencia & Ausencia & Ausencia \\
\hline 8 & Graviola & $5,5 \times 10^{5}$ & $6,1 \times 10^{4}$ & Ausencia & Ausencia & Ausencia & Ausencia \\
\hline 9 & Noni & $1,6 \times 10^{5}$ & $1,0 \times 10^{2}$ & Ausencia & Ausencia & Ausencia & Ausencia \\
\hline 10 & Demoledor de grasas & $2,1 \times 10^{5}$ & $1,7 \times 10^{4}$ & Ausencia & Ausencia & Ausencia & Ausencia \\
\hline 11 & Prostasan & $6,6 \times 10^{4}$ & $8,0 \times 10^{3}$ & Ausencia & Ausencia & Ausencia & Ausencia \\
\hline 12 & Hercampuri & $8,3 \times 10^{4}$ & $1,5 \times 10^{3}$ & Ausencia & Ausencia & Ausencia & Ausencia \\
\hline 13 & Tos- Asma bronquios & $1,4 \times 10^{5}$ & $4,0 \times 10^{3}$ & Ausencia & Ausencia & Ausencia & Ausencia \\
\hline
\end{tabular}

Observación: Para unos resultados más confiables se realizó por duplicado los ensayos para cada producto tomando la media aritmética para los datos de recuento de microorganismos. A: Recuento total de bacterias Aerobio Mesófilo Viable

B: Recuentos de mobosy levaduras

C:Investigación de Salmonella spp

D: Investigación de E. coli

E: Investigación de Stapbylococcus aureus

F: Investigación de Pseudomonas aeruginosa aeruginosa

Fuente: Elaboración propia

bó de manera invertida a $37^{\circ} \mathrm{C}$ por 48 horas; seleccionando las colonias de color grisáceo-negro, para su posterior confirmación con la prueba de la coagulasa. Los resultados se expresaron como presencia o ausencia por gramo de muestra (ICMSF, 2000).

\section{Investigación de Pseudomonas aeruginosa}

Se utilizó el Agar Cetrimide (Merck), usando el asa de Drigalsky, se extendió $0,1 \mathrm{ml}$ de inoculo vertido de las respectivas diluciones en placas de agar fundido, se las incubó de manera invertida a $37^{\circ} \mathrm{C}$ por 48 horas. Se expresó los resultados como presencia o ausencia por gramo de muestra (ICMSF, 2000).

Investigación de Salmonella spp

Se siguió el protocolo de los estándares internacionales según ISO 6579 usando agua peptonada tamponada

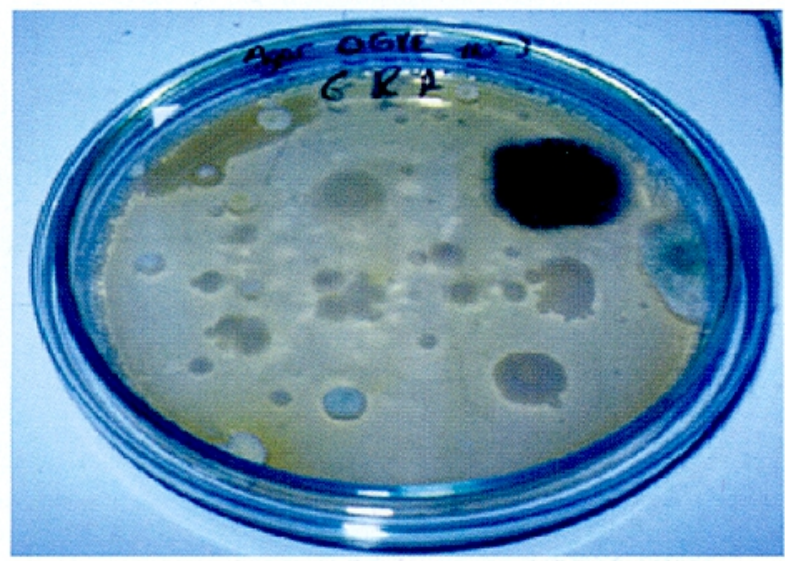

Figura 1. Los trece productos naturales analizados para ver su calidad microbiológica
(ATP) como medio de pre-enriquecimiento y el Rappaport Vassiliadis como medio de enriquecimiento selectivo, la cual se incubaron a $43^{\circ} \mathrm{C}$ por 18 - 24 horas para su posterior siembra en Agar Salmonella Shigella incubándolo a $35-37^{\circ} \mathrm{C}$ por 24 horas. Se seleccionó colonias incoloras para su posterior identificación con pruebas bioquímicas, expresando los resultados como presencia o ausencia en $10 \mathrm{~g}$ de muestra.

\section{RESULTADOS}

Un total de 13 muestras de productos naturales encapsulados (tabla 3, figura 1) fueron sometidas a los análisis microbiológicos, por duplicado, expresando, en los casos de recuento en placa, la media aritmética de los dos resultados. Para la investigación de patógenos específicos como Salmonella spp, E. coli, S. aureus, P. aeruginosa, éstos no se detectaron en las muestras, dando como resultado ausencia por gramo.

Tabla 3. Coliformes totales usando el método de número más probable de los productos naturales encapsulados

\begin{tabular}{ccc}
\hline $\mathbf{N}^{\circ}$ de muestra & Producto & *G: NMP/g \\
\hline 1 & Ririosan & 1100 \\
2 & Moringa & 40 \\
3 & Glucosamin & 1100 \\
4 & Quemador de grasa & 1100 \\
5 & Higasan & 90 \\
6 & Yacon & 90 \\
7 & Alcachofa & $>1100$ \\
8 & Graviola & $>1100$ \\
9 & Noni & $<1,8$ \\
10 & Demoledor de grasas & 150 \\
11 & Prostasan & 200 \\
12 & Hercampuri & 23 \\
13 & Tos- Asma bronquios & $<1,8$ \\
\hline
\end{tabular}

${ }^{*} G$ : Coliformes totales

Fuente: Elaboración propic 
Cáceda, C. \& Samillán S. Calidad microbiológica de productos naturales encapsulados expendidos en casas naturistas de la ciudad de Tacna.

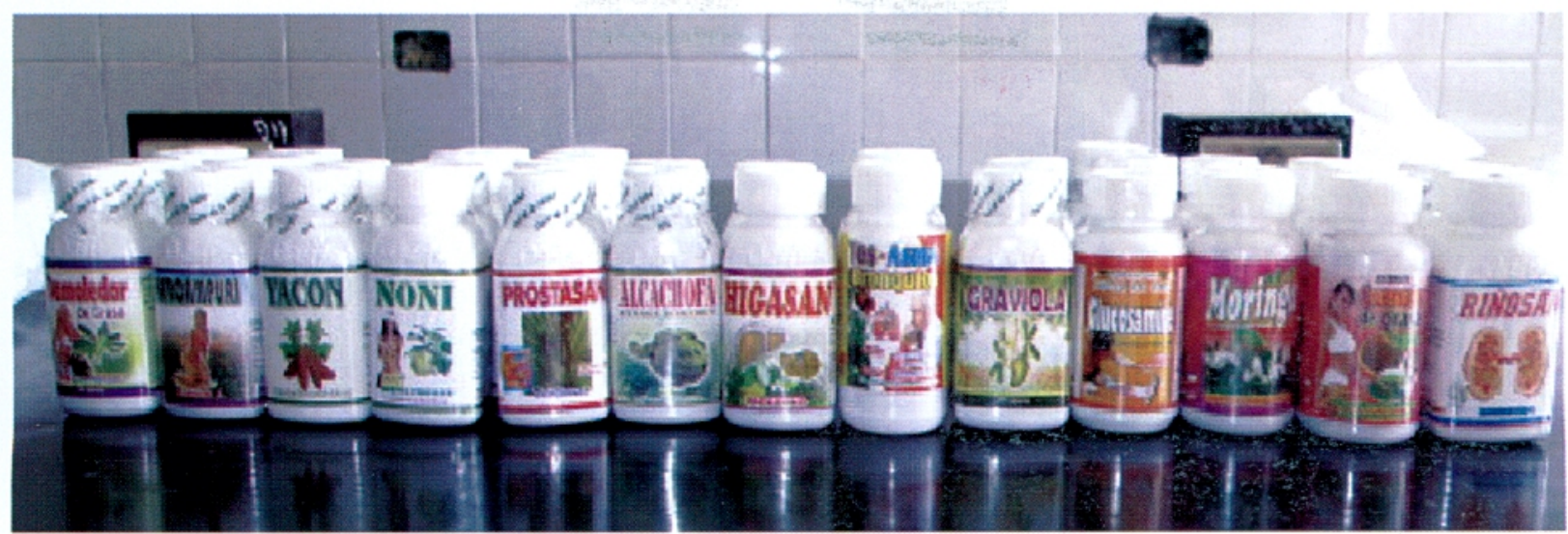

Figura 2. Recuento de hongos totales en agar AGYE de producto Graviola en una dilución $10^{-3}$

Tabla 4. Laboratorio de los productos analizados otorgados por el DIGEMID

\begin{tabular}{lcc}
\hline \multicolumn{1}{c}{ Producto } & $\begin{array}{c}\text { Laboratorios de los } \\
\text { productos naturales }\end{array}$ & $\begin{array}{c}\text { Presencia de número } \\
\text { de registro sanitario }\end{array}$ \\
\hline $\begin{array}{l}\text { Riñosan } \\
\text { Moringa } \\
\text { Glucosamin }\end{array}$ & $\begin{array}{c}\text { Oabis de la salud } \\
\text { Laboratorio natura hoja de oro }\end{array}$ & $\mathrm{Si}$ \\
Quemador de & Laboratorio natura hoja de oro & No \\
grasa & Oasis - salud & No \\
Higasan & Oasis - salud & $\mathrm{Si}$ \\
Yacon & Oasis de la salud & $\mathrm{Si}$ \\
Alcachofa & Oasis - salud & $\mathrm{Si}$ \\
Graviola & Oasis de la salud & $\mathrm{Si}$ \\
Noni & Oasis de la salud & $\mathrm{Si}$ \\
Demoledor de & & $\mathrm{Si}$ \\
grasas & Oasis - salud & $\mathrm{Si}$ \\
Prostasan & Oasis - salud & $\mathrm{Si}$ \\
Hercampuri & Laboratorio natura hoja de oro & $\mathrm{No}$ \\
Tos- Asma & & \\
bronquios & &
\end{tabular}

Para el caso de RAMV el $84,61 \%$ de las muestras analizadas sobrepasaron los límites máximos permisibles dados por la OMS (tabla 1), siendo el producto natural Alcachofa con la mayor carga microbiana $\left(8,7 \times 10^{5} \mathrm{UFC} / \mathrm{g}\right)$ perteneciente al laboratorio Oasis de la salud, teniendo este laboratorio registro sanitario $\mathrm{y}$, en el recuento de mohos y levaduras (figura 2) se encontró que el 92,3\% sobrepasaron los límites permisibles, siendo el valor más alto $6,1 \times 10^{4}$ $\mathrm{UFP} / \mathrm{g}$, el cual perteneció al producto natural Graviola, cuyo laboratorio es Oasis - salud, la cual también presentó registro sanitario.

Si bien es cierto que hubo ausencia de E. coli en las muestras analizadas, esto no descarta el elevado número de coliformes totales que se encontró (tabla 3), siendo los dos productos antes mencionados (Alcachofa y Graviola) los que presentaron los valores más altos $(>1100 \mathrm{NMP} / g)$.

De todos los productos analizados se observó además que el $69,23 \%$ presentaron número de registro sanitario siendo estos productos pertenecientes a los laboratorios "Oasis - salud"y "Oasis de la salud" (ver tabla 4).

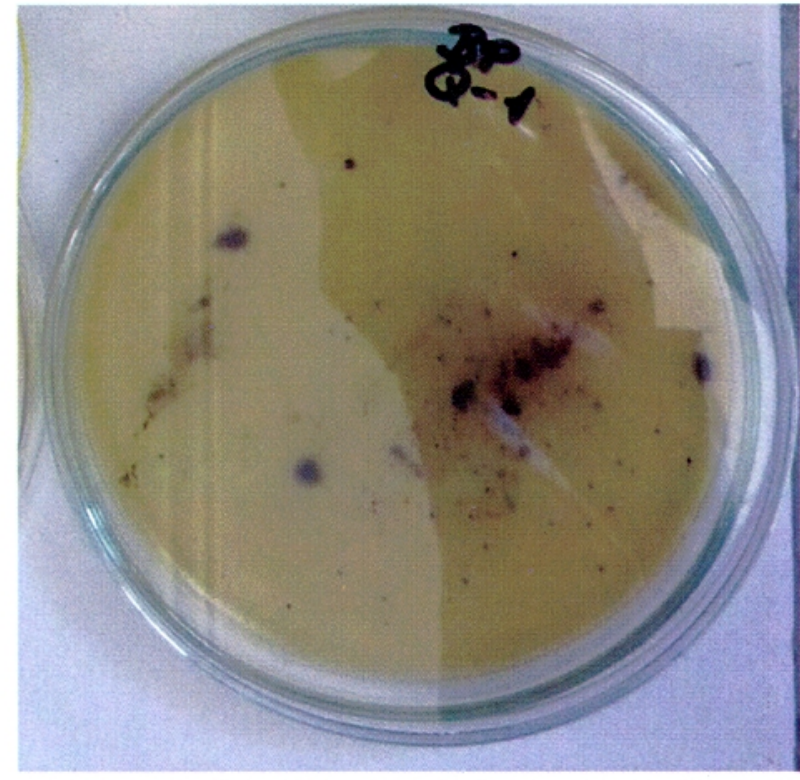

Figura 3. Colonias de Stapbylococcus spp en el producto natural "Quemador de Grasa".

\section{DISCUSIÓN}

Actualmente no existe un registro de las infecciones cuya causa se haya comprobado, sean de algún producto natural, pero si se han registrado infección inducida por fármacos (Remili, et al., 1994) cuyo control microbiológico es más estricto que los productos naturales, a pesar de esto no se encontró la presencia de algún patógeno que pudiera poner en riesgo la salud de los consumidores, no obstante se encontró Stapbylococcus coagulasa negativo (figuras 3 y 4) siendo lo más probable que éste sea $S$. epidermidis por las características de la colonia (colonias negras de tamaño irregular con zona opaca alrededor de la colonia y por ser coagulasa negativa) (Laboratorio Merck, 2012), cuya muestra pertenece al laboratorio "Natura hoja de oro" pudiendo ser la causa de esta presencia la mala práctica de manufactura por parte de los operarios en el procesamiento del producto de dicho laboratorio. No obstante, en un estudio sobre la calidad microbiológica de productos naturales en Tacna (Sanchez Pino, 2004) reportó que el 93\% de 70 muestras analizadas no cumplían con los límites máximos permisibles 
Cáceda, C. \& Samillán S. Calidad microbiológica de productos naturales encapsulados expendidos en casas naturistas de la ciudad de Tacna.

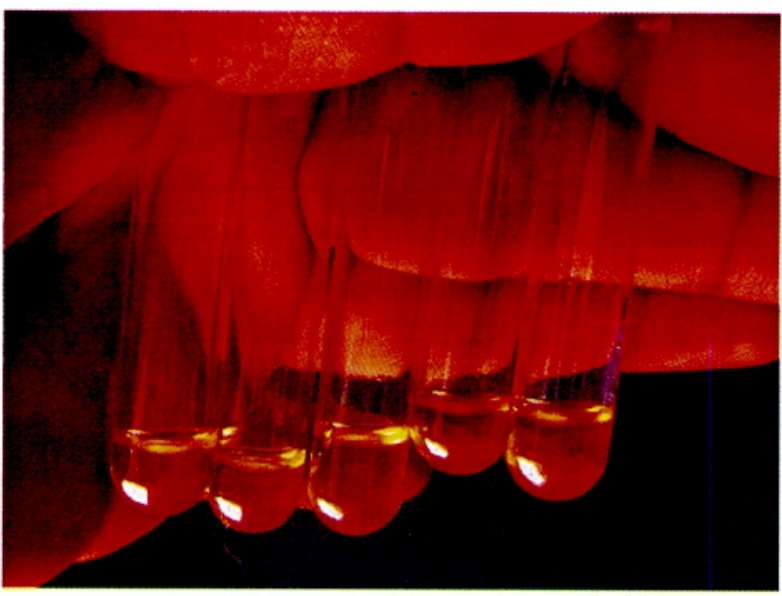

Figura 4. Prueba de la coagulasa de todas las cepas sospechosas aisladas en medio Baird Parker del producto "Quemador de Grasa".

dados por la OMS e incluso encontró a E. coli y Pseudomonas aeruginosa en un $6 \%$ y $3 \%$ respectivamente dando como explicación que la posible causa sea la manera artesanal de cómo fueron elaborados dichos productos.

De los productos analizados, el 69,23\% presentaron registro sanitario y al compararlo con los reportes dado por Valenzuela (2005) (23,7\% con presencia de registro sanitario) se observa una diferencia del $39,23 \%$ más de productos que ahora cuentan con este registro, dando a entender que tanto ha mejorado el control de estos productos desde el estudio realizado por Valenzuela en el 2005.

Sanchez Pino (2004) afirmó que la mayoría de los laboratorios de los productos que analizó no cumplen con los requerimientos necesarios para un producto terapéutico natural según el Decreto Supremo 010-97-S.A. además que la cantidad de cápsulas declarada en el envase no siempre correspondió a la encontrada en las muestras, lo que le hizo suponer que la fabricación de sus productos analizados fue hecha de manera artesanal. A diferencia de este estudio, solo se encontró un no cumplimiento con los requerimientos de etiquetado dados en el Art. $92^{\circ}$ de dicho Decreto.

En el recuento de aerobios mesófilos viables se encontró que el $84,61 \%$ de las muestras analizadas sobrepasaron los límites máximos permisibles dadas por la OMS (tabla 2) siendo los productos con mayor contaminación Graviola y Aicachofa los cuales también presentaron mayor recuento de mohos y levaduras, esto indica una elevada contaminación del producto, pero al no encontrar E. coli, se descarta una posible contaminación fecal, pudiendo ser de origen natural debido a la elevada presencia de coliformes totales (tabla 3), siendo estos resultados (elevada número en el recuento hongos y RAMV) similares a trabajos mencionados anteriormente (Rosa, et al., 1995; Sanchez Pino, 2004)

Dado que hoy en día se fabrican productos naturales a escala industrial, el foco de control se ha desplazado a la evaluación del lugar de fabricación y el proceso de producción (Ratajczak et al., 2014; Rashed et al., 2015). Los fabricantes de éstos son responsables de elaborar productos naturales de calidad adecuada, sin embargo, de los resultados obtenidos en el presente estudio que aún no se cumple esto en los productos naturales expendidos en nuestra localidad, evidenciando el escaso control por parte de las autoridades correspondientes, la falta de conciencia de las casas naturistas al vender estos productos que no presentan registro sanitario, la falta de interés y de información por parte de los consumidores directos al comprar productos que pueden ocasionarles daño, al no tener un registro sanitario.

\section{CONCLUSIONES}

Los productos naturales expendidos en las casas naturistas no cumplen con las condiciones microbiológicas mínimas para su venta al público, pudiendo convertirse en una fuente de infecciones al consumidor.

Los elevados números de aerobios mesófilos viables y de hongos totales son resultado de una posible contaminación de origen natural, siendo un riesgo para la salud de sus consumidores al poder encontrarse posibles patógenos oportunistas y/o micotoxinas.

Si bien es cierto ahora hay un mejor control microbiológico por parte del DIGEMID este aún no es suficiente para toda la demanda de estos productos por parte de la población tacneña.

\section{AGRADECIMIENTO}

Dirección General de Medicamentos Insumos y Drogas (DIGEMID) por las muestras donadas para realizar este trabajo.

\section{REFERENCIAS BIBLIOGRÁFICAS}

Burt, H., \& Kroes. (2014). The legal framework governing the quality of (traditional) herbal medicinal products in the European Union. Journal of Ethnopharmacology, $158,449-453$.

Diugaszewska, J., Muszyński, Z., \& Ratajczak, M. (2008). Microbiological purity of oral drugs manufactured in industrial and pharmacy environment. Congress of the Polish Society of Microbiologists: Microbes - Challenges and Hopes., 4-7.

ICMSF. (2000). Micro-organismos de los alimentos. España: Acribia, S.A.

Laboratorio Merck, S. A. (2012). Baird Parker Agar Base. Argentina: Laboratorio Merck S.A.

OMS. (2007). WHO guidelines for assessing quality of herbal medicines with reference to contaminant and residues. Spain: WHO Library.

Rashed, N., Nagma, Z., \& Kamal, K. D. (2015). Microbiological quality of pharmaceutical products in Bangladesh: current research perspective. Asian Pacific Journal of Tropical Disease, 4(5), 264-270.

Ratajczak, M., Kubicka, M. M., Kaminska, D., \& Sawicka, ,. P. (2014). Microbiological quality of non-sterile pharmaceutical products. Saudi Pharmaceutical Journal.

Remili, H., Boussard,, P., \& Devleeschouwer, M. (1994). Microbiological quality of spray-dried pharmaceutical plant extracts. European Journal of Pharmaceutical Siciences, 1, 265-268.

Rosa, M. d., Medina, M. d., \& Vivar, C. (1995). Microbiologi- 
Cáceda, C. \& Samillán S. Calidad microbiológica de productos naturales encapsulados expendidos en casas naturistas de la ciudad de Tacna.

cal quality of pharmaceutical raw materials. Pbarmaceutics Acta Helvetiae, 70, 227-232.

Sanchez Pino, L. (2004). Calidad microbiologica de productos naturales de uso en salud expendidos en casas naturistas de la ciudad de Tacna. Tacna, Perú: UNJBG.

Valenzuela, F. O. (2005). Comercializacion de los productos natura- les en Lima, Metropolitana. Lima, Perú: INS.

Zavaleta Martinez, A. (1999). Control de calidad de productos naturales de uso en salud en el Perú. En C. n. INS, registro y control de calidad de recursos y productos naturales de uso en salud. (págs. 33-34). Lima: INS.

\section{Correspondencia:}

César Julio Cáceda Quiroz: cesarjulce_caceda@yahoo.es

Sergio Enrique Samillán Fernández: sergiosamillan@gmail.com
Fecha de Recepción: 03/09/2015

Fecha de Aceptación: 01/12/2015 